\title{
Fate of Oligodendrocytes during Retinal Axon Degeneration and Regeneration in the Goldfish Visual Pathway
}

\author{
Richard Ankerhold, ${ }^{1}$ Claudia A. O. Stuermer ${ }^{2}$ \\ ${ }^{1}$ Carl Zeiss Jena, Tatzendpromenade 1a, 07745 Jena, Germany \\ ${ }^{2}$ Department of Biology, University of Konstanz, 78457 Konstanz, Germany
}

Received 26 April 1999; accepted 29 June 1999

\begin{abstract}
Retinal axons in goldfish regenerate after optic nerve lesion, restore synaptic connections, and become myelinated by oligodendrocytes. The fate of oligodendrocytes during these events is not known and may require generation of new oligodendrocytes or dedifferentiation and redifferentiation of the existing ones. To determine the reaction of oligodendrocytes to optic nerve lesion, we used the terminal transferase technique to detect apoptosis, bromodeoxyuridine incorporation to reveal mitosis, antibodies to identify myelin and oligodendrocytes, and Lucifer yellow injections to reveal cell morphology. Along with the reappearance of the myelin molecules $36 \mathrm{~K}$ protein, galactocerebroside, and myelin basic protein, myelinating oligodendrocytes (identified by Lucifer yellow injections) reappear 21 days postlesion. Prior to this time, the dye-filled cells had few processes oriented along the regenerating axons. They resembled oligodendrocytes seen both in vitro and in vivo which express the L1-related E587 antigen and synthe-
\end{abstract}

size the 36K myelin protein in coculture with axons. No signs of oligodendrocyte apoptosis were detected after lesion and only few of the oligodendrocytes present had recently arisen. 36K/E587 double-labeled oligodendrocytes which were most likely dedifferentiating oligodendrocytes were identified in 8-day postlesion nerves among E587-positive elongate cells whose numbers increased until 14 days postlesion. These findings suggest that oligodendrocytes dedifferentiate-like Schwann cells-from cells which express myelin molecules to elongate cells which express the L1/E587 antigen. They redifferentiate to myelinate axons from roughly 3 weeks onward. These findings suggest an adaptive plasticity of goldfish oligodendrocytes beneficial to the repair of the visual pathway.

Keywords: oligodendrocytes; adaptive plasticity; dedifferentiation; optic nerve lesion; axon regeneration; remyelination; adaptive plasticity; Schwann cells
Oligodendrocytes myelinate central nervous system (CNS) axons in both fish and mammals, yet they respond very differently to CNS fiber tract lesion in each species. In mammals, oligodendrocytes and myelin are potent inhibitors of CNS axon regrowth (Schwab et al., 1993), but unlike the Schwann cells in the peripheral nervous system (PNS) (Bunge and Hopkins, 1990), oligodendrocytes are not able to

Correspondence to: C. A. O. Stuermer Contract grant sponsor: DFG

Contract grant sponsor: Fonds der Chemischen Industrie

(C) 1999 John Wiley \& Sons, Inc. CCC 0022-3034/99/040572-13 adapt to a lesion. In fish, where CNS axons successfully regenerate, oligodendrocytes and myelin do not impair axon regrowth (Bastmeyer et al., 1991; Wanner et al., 1995). They successfully myelinate the regenerating retinal axons (Wolburg, 1981) which restore synaptic connections in the optic tectum (Gaze, 1970; Stuermer and Easter, 1984). However, little is known about the events which take place in vivo before remyelination is complete.

When myelinating axons, fish oligodendrocytes synthesize myelin molecules such as galactocerebroside (Gal-C), myelin basic protein (MBP), and the 
teleost-specific $36 \mathrm{~K}$ protein (Jeserich and Waehneldt, 1986a). However, when isolated from the fish optic nerve/tract and kept in culture, they undergo dramatic changes in shape and cease expressing the advanced myelin molecules. Fish oligodendrocytes observed in vitro appear as dedifferentiated, O4-positive, elongate, and proliferating cells. Like Schwann cells, they express the L1-related E587 antigen (Bastmeyer et al., 1993, 1994; Ankerhold et al., 1998). They do not produce advanced myelin proteins in the absence of neurons but show signs of redifferentiation and express the teleost-specific $36 \mathrm{~K}$ myelin protein in longterm cocultures with axons (Bastmeyer et al., 1993, 1994).

Optic nerve lesion (ONS) in goldfish induces the expression of E587 antigen in oligodendrocytes of the optic nerve/tract (Ankerhold et al., 1998). This was demonstrated by in situ hybridization experiments and by immunocytochemistry with the E587 antibody. Since regenerating retinal axons are also E587 positive (Vielmetter et al., 1991), their presence makes identification of glial cells difficult. For this reason, we examined nerve/tracts in early stages of regeneration or preparations in which axon regrowth was blocked (Ankerhold et al., 1998). The morphology of the E587 positive glial cells resembled that of dedifferentiated oligodendrocytes in culture (Ankerhold et al., 1998). E587 antigen expression in glial cells began by 6 days, peaked at 14 days, and was reduced by 40 days after ONS, thus occurring in parallel with retinal axon degeneration and regeneration. Together with in vitro results, this indicates that fish oligodendrocytes are able to dedifferentiate and to redifferentiate in response to the state of the system. It has been suggested, however (Sivron and Schwartz, 1994), that fish oligodendrocytes undergo apoptosis in response to ONS. This would be advantageous for the animal if its oligodendrocytes inhibit axon growth as strongly as those in mammals. It implies that new oligodendrocytes must be generated to myelinate the axons.

The fish visual pathway is a prime example of a self-repairing CNS system (Grafstein, 1986). The fate of oligodendrocytes is therefore important for understanding how the response of this type of glial cell to lesion has evolved.

In the present experiments, we applied the terminal transferase (TUNEL) technique and used bromodeoxyuridine (BrdU) marking to evaluate the extent of lesion-induced oligodendrocyte apoptosis and proliferation in vivo. We determined expressional and morphological changes of individual oligodendrocytes during the period in which myelin degradation and myelin molecule reexpression takes place. Evidence obtained suggests that goldfish oligodendrocytes in vivo dedifferentiate and redifferentiate during retinal ganglion cell (RGC) axon degeneration and regeneration.

\section{MATERIALS AND METHODS}

\section{Animals}

Goldfish raised in our breeding colony at the University of Konstanz were anesthetized in $0.03 \%$ MS222 (Sigma) prior to optic nerve transection (as described in Vielmetter and Stuermer, 1989) in compliance with animal welfare legislation. Fish of two sizes were used: small fish (0.5-1 year old) with a length (from mouth to base of tail) of 3-5 cm or large fish (1-1.5 years old) with a length of $6-8 \mathrm{~cm}$.

\section{Intracellular Dye Injection}

The optic nerves/tracts and the anterior tectum opticum of small goldfish were dissected and the nucleus rotundus was removed. The isolated nerve/tract preparation was placed in a chamber containing cold L15 (Leibowitz medium; Gibco) on a Sylgard-coated slide in a small well and immobilized with pins. To gain access to the glial cells, part of the optic tract and tectum was carefully desheathed. Intracellular injections were performed under a modified compound microscope (Zeiss) equipped with a $\times 40$ long working distance water immersion lens (Zeiss). Borosilicate glass electrodes (Clark Electromedical Instruments) were filled with a $4 \%$ (w/v) aqueous solution of Lucifer yellow and backfilled with $2 \mathrm{mM} \mathrm{LiCl}$. Such electrodes had a resistance between 70 and $100 \mathrm{M} \Omega$. Using a hydraulic micromanipulator (Narashige), individual cell bodies in the optic tract were impaled. The dye was injected iontophoretically with 5-10 $\mathrm{nA}$ hyperpolarizing current pulses $(200 \mathrm{~ms}$ duration, $3 \mathrm{~Hz}$ frequency) for 5-15 min. After injection, the tissue was left for $15 \mathrm{~min}$ to allow diffusion of the dye within the cell and was then fixed in $4 \%$ paraformaldehyde (PFA) in phosphate-buffered saline (PBS) $(\mathrm{pH} 7.4)$ overnight at $4^{\circ} \mathrm{C}$. The injection procedure was biased toward oligodendrocytes because cell bodies in between axon bundles were preferentially impaled. Lucifer yellow-filled cells were examined and photographed with an Axiophot microscope (Zeiss) equipped with epifluorescence and the appropriate filter sets.

\section{Whole-Mount Lucifer Yellow Immunohistochemistry}

To obtain a long-lasting label, the tissue was treated with peroxidase-conjugated antibodies against Lucifer yellow and subjected to a diaminobenzidine hydrochloride (DAB) reaction protocol. In brief, the fixed preparations were incubated in $0.3 \%$ hydrogen peroxide in methanol for $30 \mathrm{~min}$ to reduce endogenous peroxidase activity and washed in PBS with $0.1 \%$ Triton X-100 (PBT). After a blocking step 
with $3 \%$ normal goat serum and 3\% bovine serum albumin in PBS for $1 \mathrm{~h}$, the tissue was incubated with a peroxidaseconjugated rabbit anti-Lucifer yellow polyclonal antibody (Molecular Probes; dilution 1:500) overnight at $4^{\circ} \mathrm{C}$. The tissue was washed in PBT, preincubated in $\mathrm{DAB}$ for $1 \mathrm{~h}$ in the dark, and then subjected to a $\mathrm{DAB}$ reaction according to standard protocols (Vector Laboratories). The preparations were dehydrated in ethanol, cleared in methyl salicylate, and mounted in Entellan (Merck). Representative cells were photographed and the morphology was reconstructed at the microscope (Zeiss Axioplan) equipped with a digital imageenhancing system (Hamamatsu). During the course of the project, a total of 155 cells were successfully dye-filled (65 cells in the intact optic tract and 90 cells after ONS) and processed.

\section{In Situ Detection of Apoptotic Cell Death}

The DNA fragmentation of cells undergoing apoptosis was visualized by the TUNEL method (Gavrieli et al., 1992) on cryosections of the optic nerve of large goldfish between $7 \mathrm{~h}$ and 10 weeks after ONS. Optic nerves were dissected out, either fixed in 4\% PFA in PBS for $2 \mathrm{~h}$ or directly immersed in TissueTek (Miles) and frozen in liquid nitrogen. Then, 14- $\mu \mathrm{m}$ transverse cryostat sections were collected on coated slides (Superfrost; Menzel-Gläser), air-dried, fixed in $4 \%$ PFA in PBS for $20 \mathrm{~min}$, and rinsed in PBS. For longitudinal sections, the tissue was embedded as described previously (Ankerhold, 1989) and processed like the transverse sections. The sections were dilipidated in ethanol/acidic acid $(2: 1)$ at $-20^{\circ} \mathrm{C}(5 \mathrm{~min})$ or in $0.1 \%$ Triton $\mathrm{X}-100$ in $0.1 \%$ sodiumcitrate on ice $(3 \mathrm{~min})$. After washes in PBS, the TUNEL reaction and detection of the labeled nucleotides were carried out according to the manufacturer's instructions (Oncor; Boehringer Mannheim). The sections were counterstained with DAPI $(0.5 \mu \mathrm{g} / \mathrm{mL}$; Sigma $)$ for $10 \mathrm{~min}$ to visualize the nuclei, mounted in Mowiol (Hoechst) with the antifading $n$-propyl-gallate (Sigma), and examined at the microscope (Zeiss Axiophot). Sections in which either the TUNEL enzyme or the labeled nucleotides were omitted served as negative controls. Sections treated with $10 \mathrm{U} / \mu \mathrm{L}$ DNAse (Boehringer Mannheim) for $30 \mathrm{~min}$ at $37^{\circ} \mathrm{C}$ prior to the TUNEL reaction were positive controls. For quantitative analyses, cross sections more than $500 \mu \mathrm{m}$ distal from the transection site in the brain-side optic nerve were used. In intact and transected optic nerves, some TUNEL-positive cells were always seen at the margin of the section. These cells were not taken into account. At least two sections per optic nerve and three to six optic nerves per time point were analyzed.

\section{In Vivo BrdU Incorporation Assay}

Immediately after ONS, small goldfish were transferred to tanks with $0.1 \mathrm{mg} / \mathrm{mL} \mathrm{BrdU} \mathrm{(Sigma)} \mathrm{in} \mathrm{the} \mathrm{water.} \mathrm{Fish} \mathrm{were}$ maintained in BrdU water up to 12 days and the water (and $\mathrm{BrdU}$ ) was replaced twice a week. Another group of fish was transferred to BrdU water by day 12 after ONS and remained exposed to BrdU for 20 days. That BrdU is continuously available and incorporated by dividing cells was verified by the analysis of retinae of rapidly growing goldfish (30-50 days old; $n=5$ ) which were kept in BrdU water for 10 days. When sections through the eye were subjected to BrdU immunohistochemistry (see below), continuous rows of labeled cells in the ganglion cell layer and in the inner nuclear layer were BrdU positive, indicating that all new cells of the continuously growing eye had incorporated the marker. To study lesion-induced cell proliferation in optic nerve sections, goldfish $(n=5)$ were kept in BrdU-water for 3, 5, 8, and 10 days after ONS. The optic nerves were dissected out and 14- $\mu \mathrm{m}$ transverse cryosections $(300-800 \mu \mathrm{m}$ distal to the transection site in the brain-sided nerve) were collected on coated slides, air-dried, dehydrated for $5 \mathrm{~min}$ in methanol $\left(-20^{\circ} \mathrm{C}\right)$, and rinsed in PBS. The sections were exposed to $2 N$ hydrochloric acid to denature the DNA for 30 min, rinsed in $\mathrm{Na}_{2} \mathrm{~B}_{4} \mathrm{O}_{7}(100 \mathrm{mM})$ for $10 \mathrm{~min}$, and then washed in PBS. Anti-BrdU (BoehringerMannheim, 1:10) was applied for $1 \mathrm{~h}$ followed by washes in PBS. The cells were treated with fluorescein (FITC)-conjugated goat-anti-mouse antibody (Dianova, 1:100) for $1 \mathrm{~h}$, washed in PBS, exposed to DAPI to visualize cell nuclei, and mounted in Mowiol.

To determine whether oligodendrocytes proliferate after ONS, goldfish were kept in BrdU-water from 0 to 12 and 12 to 32 days following ONS. Because of the presence of myelin which is stained by the antibodies against myelin molecules, including $\mathrm{O} 4$, it was impossible to use any of these markers for a quantification of oligodendrocytes in optic nerve sections. Therefore, optic nerve/tracts were isolated as described (Bastmeyer et al., 1993, 1994). In brief, small pieces from the regenerating optic nerves/tracts were incubated at $28^{\circ} \mathrm{C}$ for $20 \mathrm{~min}$ in $\mathrm{L} 15$ with $0.3 \%$ collagenase (Worthington Seromed) and $0.1 \%$ dispase (Boehringer Mannheim). The enzyme mixture was replaced by L15 with $10 \%$ fetal calf serum (FCS) and centrifuged at $200 \times g$ for $5 \mathrm{~min}$. Then, the cell suspension was plated onto polylysine/ laminin-coated coverslips. Cells were allowed to adhere for 4-5 h. Live cells were exposed to O4 antibody (hybridoma supernatant diluted 1:3 in L15) for $30 \mathrm{~min}$. After brief washes in L15, cells were fixed and permeabilized with methanol $\left(5 \mathrm{~min}\right.$ at $-20^{\circ} \mathrm{C}$ ) and fixed in $2 \%$ PFA (in PBS for $5 \mathrm{~min}$ ) and exposed to rhodamine (TRITC)-conjugated goat-anti-mouse secondary antibody (Dianova; 1:200, $1 \mathrm{~h}$ ). After washes in PBS, cells were postfixed in 2\% PFA for 5 min, subjected to the BrdU immunostaining procedure, and mounted as described above (Bastmeyer et al., 1994). The secondary antibody was an immunoglobulin G (IgG)-specific FITC-conjugated goat-anti-mouse antibody (Dianova; 1:100) to prevent binding to the mouse IgM O4 antibody. Three to five fish were used per experiment and the experiment was repeated three times.

\section{Immunohistochemistry on Cryosections}

Sections from optic nerve/tracts of small and large goldfish were subjected to immunostaining procedures described 
previously (Bastmeyer et al., 1991, 1994; Lang and Stuermer, 1996). The following monoclonal (mAB) and polyclonal (pAB) antibodies were applied: $\mathrm{pAB}$ anti-36K myelin protein (Jeserich and Waehneldt, 1986) (kindly provided by G. Jeserich; dilution 1:200), mAB anti-galactocerebroside (GalC) (Boehringer Mannheim; dilution 1:50), and $\mathrm{mAB} 6 \mathrm{C} 2$ against MBP (kindly provided by $\mathrm{C}$. Linington, dilution 1:5). mAB SMI-31 against neurofilaments (Sternberger-Meyer Immunochemicals; dilution 1:1000), pAB anti-GAP-43 (generated in our lab; dilution 1:500), and mAB E587 (Vielmetter et al., 1991) (concentration $20 \mu \mathrm{g} /$ $\mathrm{mL}$ ) were used to demonstrate regenerating axons.

Longitudinal and cross sections through the optic nerves and tracts, prepared at increasing times after ONS, were fixed in methanol $\left(-20^{\circ} \mathrm{C}\right)$ for $5 \mathrm{~min}$, rinsed in PBS, and blocked with $2 \%$ BSA in PBS for $1 \mathrm{~h}$ to prevent unspecific binding. The primary antibody or the mixture of primary antibodies (e.g., pAB anti-36K and mAB E587) was applied overnight at $4^{\circ} \mathrm{C}$ followed by washes in PBS. TRITC or FITC-conjugated anti-mouse, anti-rabbit, or anti-rat antisera (all 1:200; all from Dianova) were used as secondary antibodies. Sections were exposed to the secondary antibody or mix of secondary antibodies for 2-4 h, washed in PBS, counterstained with DAPI, and mounted in Mowiol.

\section{RESULTS}

Five groups of experiments were performed to elucidate the fate of oligodendrocytes during RGC axon de- and regeneration following ONS: (a) Antibodies against myelin molecules were applied to analyze the time course of myelin degradation and reformation in small and large fish and to determine when the visual pathway contains remyelinating oligodendrocytes after ONS. (b) Lucifer yellow injection was used to identify myelinating oligodendrocytes morphologically and to reveal their morphological changes. (c) The TUNEL technique was applied to determine whether oligodendrocytes undergo apoptosis in response to ONS. (d) BrdU incorporation assays were performed to analyze the extent to which new oligodendrocytes are generated. (e) Antibodies against the $36 \mathrm{~K}$ myelin protein and E587 antigen were used to identify cells which we believe are dedifferentiating oligodendrocytes.

\section{Time Course of Myelin Degradation and Reformation}

In normal goldfish optic nerve/tracts, anti-36K, antiGalC, and anti-MBP resulted in compact staining around axons in fascicles (Fig. 1). After optic nerve lesion, this pattern gradually changed as axon degeneration progressed. Staining was still substantial at 9 days after ONS (Fig. 1), but it became progressively
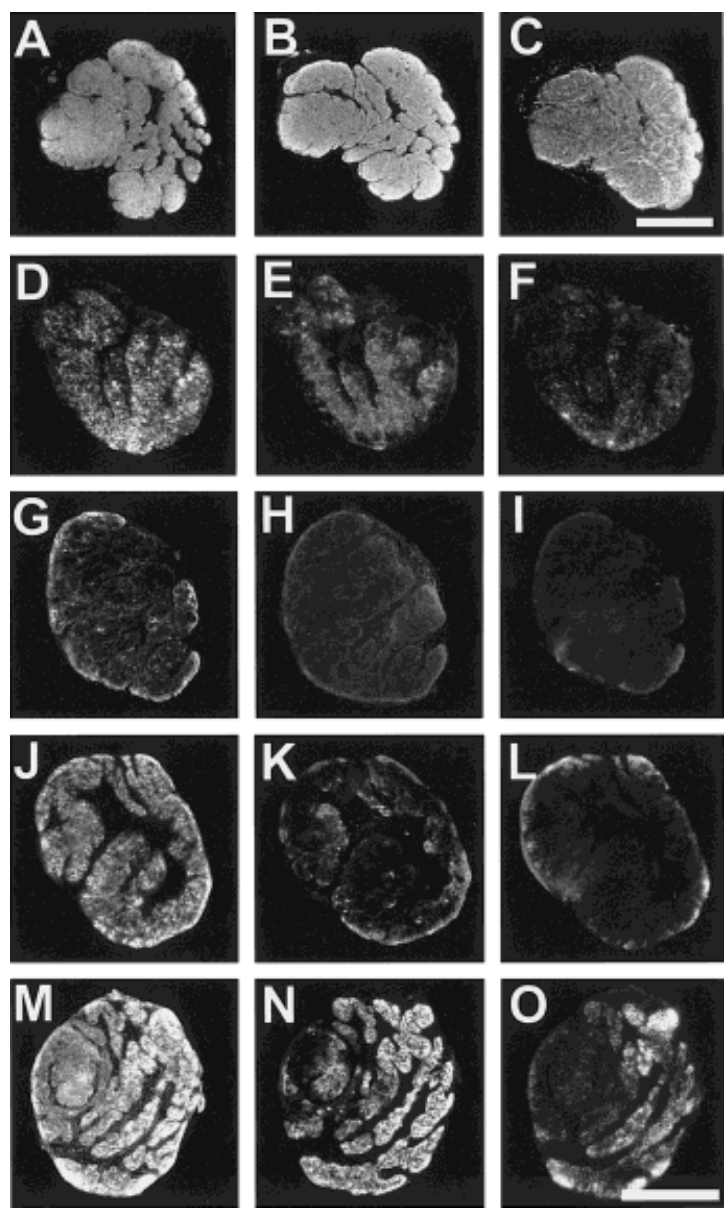

Figure 1 Detection of myelin molecules in the goldfish optic nerve after ONS. Optic nerve cross sections were exposed to antibodies against $36 \mathrm{~K}$ protein (A,D,G,J,M), GalC (B,E,H,K,N), and MBP (C,F,I,L,O). In the normal goldfish optic nerve (A-C), immunostaining with the antibodies results in the characteristic compact staining around axons in fascicles. At 9 days after ONS (D-F), staining has become granular, which is typical of myelin debris. Staining with anti-MBP declines faster than that with anti-36K (D) or anti-GalC (E). At 3 weeks after ONS (G-I), immunostaining with the antibodies is markedly reduced $(\mathrm{G}, \mathrm{H})$ or absent (I). By 3.5 weeks (J-L), staining with anti-36K has increased $(\mathrm{J})$ and is distributed in a pattern that reflects the nerve's organization in fascicles. GalC $(\mathrm{K})$ and $\mathrm{MBP}(\mathrm{L})$ are just beginning to be detectable. By 4 weeks after ONS $(\mathrm{M}-\mathrm{O})$, anti-36K intensely labels all fascicles $(\mathrm{M})$, whereas GalC $(\mathrm{N})$ and MBP $(\mathrm{O})$ are less abundant but clearly fascicular. Scale bars $=200 \mu \mathrm{m}(\mathrm{A}-\mathrm{C})$ and $100 \mu \mathrm{m}(\mathrm{D}-\mathrm{O})$.

granular, which is typical of myelin debris. Myelin debris was abundant during the first 10 days, still present 2 weeks after ONS, but greatly reduced by 3 weeks (Fig. 1).

Retinal ganglion cell axons are known to regrow within 4 days after ONS. They pass through the optic 
nerve/tract when myelin is still abundant (Strobel and Stuermer, 1994; Hirsch et al., 1995) and begin to form synapses in the anterior optic tectum as early as 14 days after ONS (Stuermer and Easter, 1984). The number of regenerating axons growing toward the tectum increases dramatically between 6 and 30 days and synapses are reestablished throughout the entire tectum (Murray and Edwards, 1982; Stuermer and Easter, 1984). The presence of regenerating axons in fish of the present study was confirmed by E587 labeling (Vielmetter et al., 1991).

In correlation with the progressive reinnervation of the tectum, the myelin markers sequentially reappeared between 3.5 and 4.5 weeks after ONS (Fig. 1) in small fish, and 6-10 weeks in the larger fish. The first to reappear was $36 \mathrm{~K}$ protein, then GalC, and finally MBP. This indicates the presence of oligodendrocytes active in reforming a myelin sheath around axons.

\section{Morphology of Individual Oligodendrocytes}

Small fish were used for the Lucifer yellow injection because the injection needle can successfully penetrate the tissue. When cells whose somata lie in rows parallel to the course of axons were impaled, $60 \%$ of the labeled cells in the intact tract were oligodendrocytes $(n=65)$. Among the remaining $40 \%$ were cells which, based on their morphology (Butt and Kirvall, 1996), were most likely astrocytes (10\%) and cells of unknown identitity $(30 \%)$. Cells with one or two processes parallel to the axons were also found, but these had additional short processes emanating from the soma in various directions and differed in this regard from the putative dedifferentiated oligodendrocytes described below.

Goldfish oligodendrocytes closely resembled their mammalian counterparts [Fig. 2(A-C)]. Fine branches connected the soma $[8 \pm 1$ (standard error [S.E.]) $\mu \mathrm{m}$ $(n=23)]$ with the longitudinal processes. There were $23 \pm 1$ myelinating segments per cell and each segment had a mean length of $122 \pm 6 \mu \mathrm{m}(n=52)$.

In cells injected between $7 \mathrm{~h}$ and 3 days after ONS $(n=36)$, the longitudinal processes were reduced in length [Fig. 2(D)], but no such cells were found with injections done 4-20 days after ONS, at which time the majority of dye-injected cells $(n=21)$ were elongate with one, two, or sometimes no identifiable processes [Fig. 2(E,F)]. The identity of these cells could not be determined by morphological criteria alone, but where processes were present, they were oriented along the course of axons. This morphology is typical of E587-positive cells in vivo (Ankerhold et al., 1998) [see Fig. 6(D)] and oligodendrocytes in vitro.

From 20 days onward, 22 of 33 dye-labeled cells were identified as oligodendrocytes with characteristic morphological features [Fig. 2(G)]. They exhibited processes which were shorter than normal but oriented along the regenerating axons. By 30 days, cells resembling normal oligodendrocytes were consistently found. The orientation of their myelinating processes was often oblique and less orderly than in intact nerve/tracts [Fig. 2(H)]. This reflects the less orderly routes of the regenerating retinal axons themselves (Stuermer and Easter, 1984).

In summary, fully differentiated oligodendrocytes, identified morphologically, reappeared in the tract concomitant with the restoration of synaptic connections by RGC axons in the tectum and the reappearance of anti-36K, anti-GalC, and anti-MBP immunoreactivity in the optic nerve/tract.

\section{Detection of Oligodendrocyte Apoptosis}

To determine whether oligodendrocytes undergo apoptosis after ONS, we applied the TUNEL technique (Gavrieli et al., 1992; Crowe et al., 1997). Whether they were replaced by new cells through proliferation was assessed in separate experiments using BrdU.

The fish optic nerve is organized into fascicles separated by interfascicular spaces (Maggs and Scholes, 1986). Oligodendrocytes and reticular astrocytes (which form the glia limitans around each fascicle) are the major cellular components of the fascicles and are absent from the interfascicular spaces (Battisti et al, 1995; Hirsch et al., 1995). According to Battisti et al. (1995), 15\% of the intrafascicular cells are microglial cells. After ONS, the fascicles are maintained and astrocytes and oligodendrocytes remain restricted to the fascicles (Battisti et al., 1995; Hirsch et al., 1995). This excludes the possibility that TUNEL-positive cells outside of the fascicle are oligodendrocytes. Large fish were used for this evaluation because their fascicles and interfascicular spaces are more easily distinguished.

To determine the ratio of TUNEL-positive cells and obtain an impression of the overall changes of cell numbers inside and outside the fascicles, counts were made of DAPI-labeled nuclei on cross sections of optic nerves well beyond ( $\geq 500 \mu \mathrm{m})$ and distal to the transection site where the fascicles and their boundaries are quite distinct (Fig. 3). In the intact optic nerve, $69.1 \%(62.3 \pm 14.7$ of $90.2 \pm 16.1)$ of the cells were located in the interfascicular spaces and only $28.6 \%$ (58.8 \pm 6.5 cells) within the fascicles (Fig. 4). 

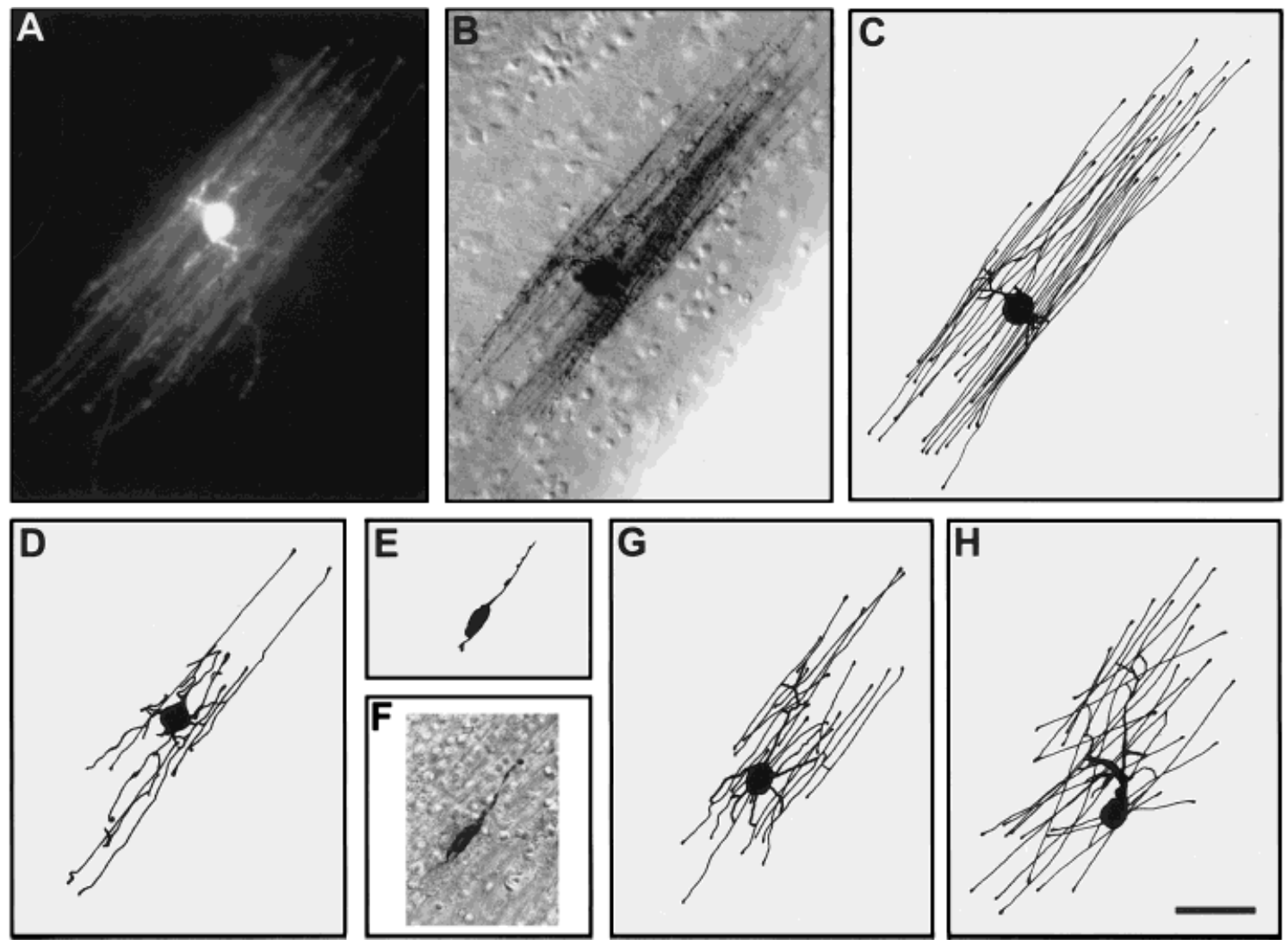

Figure 2 Morphology of goldfish oligodendrocytes in normal and postlesion optic tracts. (A,B) Lucifer yellow-injected oligodendrocyte (A) and after dye conversion (B) in the normal tract exhibit the typical features of this class of glia. (C) Camera lucida drawing of another oligodendrocyte shows its numerous well-ordered processes in the direction of the retinal axons. (D) Within 1 day after ONS, many of the myelinating segments appear shrunken and reduced in length. (E,F) Dye-injected cells at 8 (E) and 17 days (F) after ONS bear few processes and the longer ones are oriented along the path of axons. $(\mathrm{G}, \mathrm{H})$ At 21 and 30 days after ONS, oligodendrocytes extend many myelinating segments, which, as illustrated in $(\mathrm{H})$, exhibit an orientation reflecting the less orderly routes of the regenerating axons. All photos are oriented with the course of axons running diagonally from the lower left to the upper right corner of the image. (D,E,G,H) Drawings of dye-filled oligodendrocytes after conversion of Lucifer yellow. Scale bar $=20 \mu \mathrm{m}$.

A few TUNEL-positive cells $(2.3 \% ; 2.1 \pm 1.7$ cells $)$ were seen in the intact optic nerve but exclusively outside the fascicles [Fig. 3(C)]. TUNEL-positive nuclei in intact and lesioned nerves showed chromatin condensation and aggregation into small, bright apoptotic bodies [Fig. 3(A,B)]. After ONS, the total number of cells dramatically increased (Battisti et al., 1995) so that the nerve contained almost twice as many cells 2 weeks after ONS $(159.5 \pm 19.1$ cells $)$ as the control (Fig. 4). Thereafter, the number of cells declined progressively and reached near normal levels by about 10 weeks after ONS $(96.7 \pm 4.4$ cells). This increase of cells, however, occurred predominantly in the interfascicular spaces. Changes in numbers of cells within the fascicles between $7 \mathrm{~h}$ and 2 weeks after ONS were insignificant by statistical analysis $(t$ test; $p<.01$ ). The number of TUNEL-positive cells at 1 day after ONS increased fivefold (5.5) over control $(11.4 \pm 2.8$ cells versus $2.1 \pm 1.7$ in control $)$ and was back to control levels by 1 week. At all times considered, TUNEL-positive cells were found almost exclusively in interfascicular spaces and not within fascicles (Fig. 4). One section at 1 day after ONS contained one TUNELpositive cell within a fascicle which amounts to the average of $0.1 \pm 0.3$ TUNEL-positive cells. This suggests that cells in the fascicle (including oligodendrocytes) rarely undergo apoptosis.

\section{Tests for Oligodendrocyte Proliferation}

To determine whether glial cells in fascicles proliferate following ONS, small fish were kept in water 

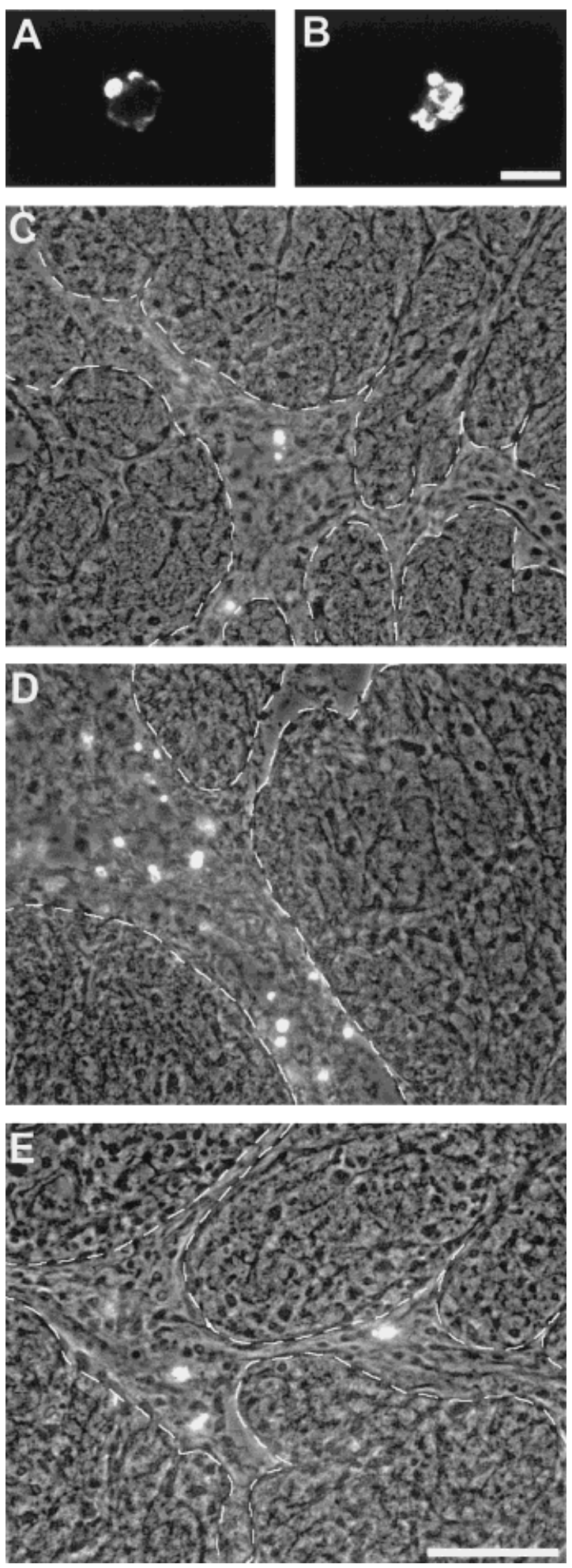

Figure 3 Detection of apoptopic nuclei by TUNEL technique. (A,B) Examples of chromatin aggregates in nuclei detected by TUNEL. Scale bar $=10 \mu \mathrm{m}$. (D,E) TUNELpositive nuclei are detected in intact optic nerves (C), as well as in nerves at 1 days (D) and 2 weeks (E) after ONS. They were always found in interfascicular spaces and not within the fascicles. The fascicle boundaries are marked by containing BrdU, so that BrdU was continuously available for incorporation (see Materials and Methods). After 3, 5, 8, and 10 days, cross sections of the optic nerve beyond (more than $300 \mu \mathrm{m}$ ) the site of lesion were subjected to BrdU immunohistochemistry. In parallel with the overall increase in the number of cells, an increased number of BrdU-positive cells was seen in both the interfascicular spaces and in the fascicles. This was expected because both microglial cells and macrophages divide in response to lesions (Gehrmann et al., 1995; Dowding et al., 1991). Those involved in phagocytosis of intrafascicular myelin are found in increasing numbers between fascicles (Battisti et al., 1995) showing that they emigrate from the fascicle compartement. This is consistent with the disappearance of myelin debris from within the fascicles as described above.

To obtain an estimate of how many of the BrdUincorporating cells were oligodendrocytes, glial cells were isolated from optic nerve/tracts of fish maintained in BrdU water for 10-12 days after ONS. They were seeded on coverslips $(n=10)$ and exposed to the $\mathrm{O} 4$ antibody and anti-BrdU. Cells were counted over five areas of $0.5 \mathrm{~mm}^{2}$. A total of $18.5 \pm 1.6 \%(n$ $=50)$ of cells had incorporated BrdU, $8.1 \pm 0.5 \%$ were O4-positive oligodendrocytes, but only 0.6 $\pm 0.2 \%$ were both $\mathrm{O} 4$ and anti-BrdU positive. The majority of the O4-positive oligodendrocytes was BrdU negative and only $7.5 \pm 2.2 \%$ of the $\mathrm{O} 4$ positive cells had incorporated BrdU (Fig. 5). These results suggest that in the 10- to 12-day period following ONS, relatively few oligodendrocytes in the regenerating goldfish optic nerve/tract were generated by mitosis.

Similar experiments were carried out with small fish which were kept in BrdU-water from 12 to 32 days after ONS. A total of $6.2 \pm 0.5 \%$ of the isolated cells were $\mathrm{O} 4$ positive, and $4.5 \pm 0.4 \%$ had incorporated BrdU, but only $0.05 \pm 0.05 \%$ were both $\mathrm{O} 4$ and anti-BrdU positive. This speaks against a delayed burst of oligodendrocytes proliferation.

\section{Lesion-Induced Dedifferentiation of Oligodendrocytes}

Results obtained from the foregoing experiments speak against a massive loss of oligodendrocytes by apoptosis and show only a moderate increase by proliferation. Because oligodendrocytes express E587 antigen in vitro as well as in vivo (Ankerhold et al., 1998), it seems likely that the onset of E587 antigen expression is a characteristic feature of dedifferentiating oligodendrocytes. Optic nerve/tract glial cells begin to synthesize E587 antigen by 6 days after ONS 


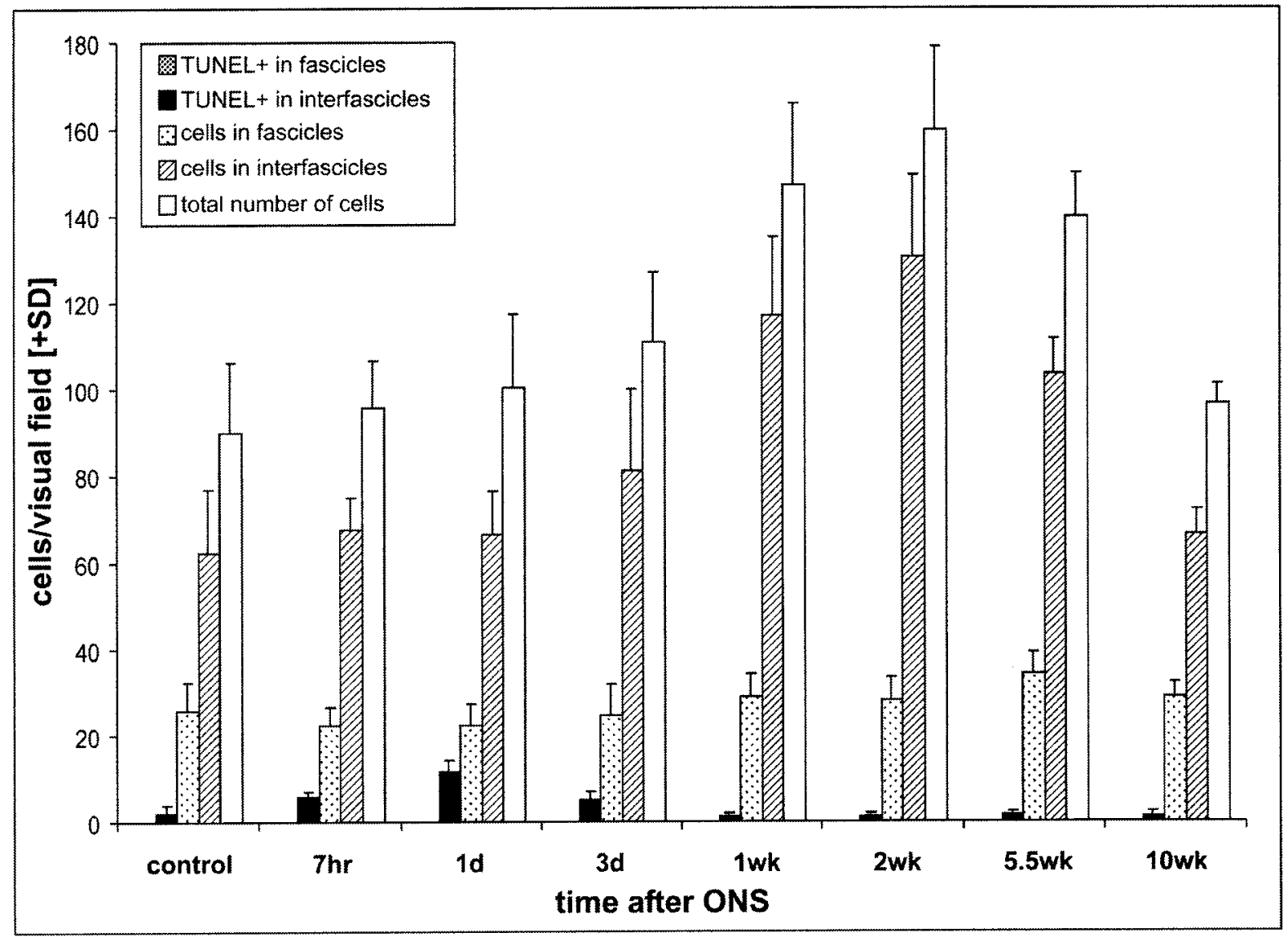

Figure 4 Quantification of cells in interfascicular spaces and in fascicles at increasing time points after ONS. The height of the bars reflects number of cells and standard deviations (SD). Compared to the overall increase of cells in the nerve after ONS, the number of intrafascicular cells remains relatively constant. TUNEL-positive cells were found exclusively in intrafascicular spaces.

tracts (large fish) between 6 and 8 days after ONS with antibodies against E587 antigen and 36K myelin protein. The number of regenerating axons which are also E587 positive (Vielmetter et al., 1991) is relatively small at these early stages after ONS. The long thin axons and the E587-positive glial cells whose nuclei were labeled with DAPI could be clearly distinguished with a $\times 100$ oil-immersion lens.

Cells bearing E587-positive elongate processes (Fig. 6) were consistently found with roughly 50 cells/section. They did not express $36 \mathrm{~K}$ protein. We also identified 36K/E587double-labeled cells of compact morphology (Fig. 6). These were difficult to detect because of the abundant 36K-positive myelin debris, and a quantitative evaluation was not possible. However, each section contained between three and six 36K/E587 double-labeled cells. In conjunction with earlier results (Bastmeyer et al., 1993, 1994; Ankerhold et al., 1998), the existence of these cells supports the view that goldfish oligodendrocytes dedifferentiate after ONS.

\section{DISCUSSION}

Following optic nerve transection in goldfish, mature oligodendrocytes are apparently capable of reverting into dedifferentiated cells which redifferentiate into myelinating oligodendrocytes during retinal axon regeneration and target contact reformation. Several lines of evidence support this view. Lucifer yellow injections into individual cells revealed cells with the morphology of remyelinating oligodendrocytes. Their appearance by about 3 weeks after ONS roughly correlates with the onset of myelin molecule reexpression (about 3.5 weeks after ONS). Prior to this time, injected cells were elongate and most extended processes in the direction of the axons. By their position 

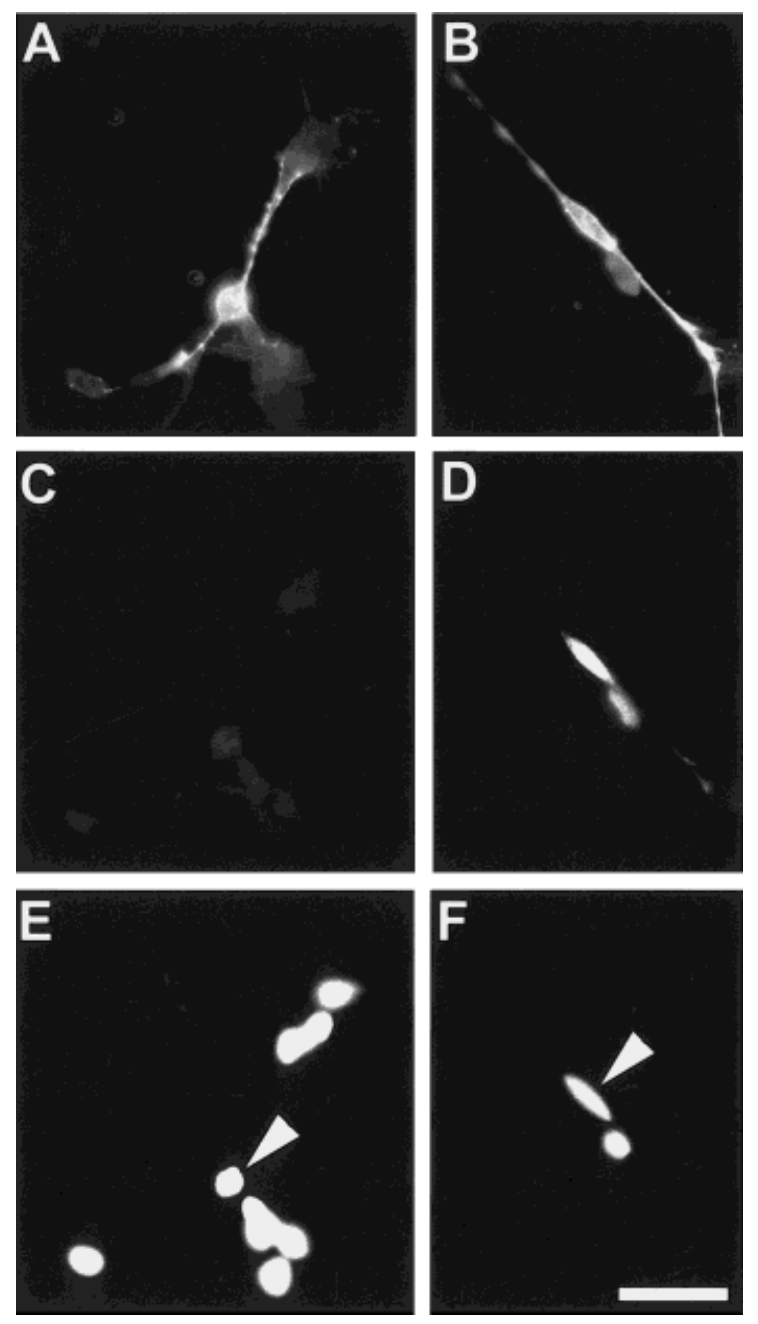

Figure 5 Identification of oligodendrocytes after optic nerve/tract dissociation. (A)An O4-positive oligodendrocyte not stained by anti-BrdU (C) and its nucleus [arrowhead, (E)] among several DAPI-labeled nuclei. (B) An O4-positive oligodendrocyte whose nucleus is anti-BrdU positive (D) and revealed by DAPI [(F), arrowhead]. Scale bar $=20 \mu \mathrm{m}$.

and orientation of their processes, these cells resembled glial cells which are induced to synthesize E587 antigen in response to ONS. These appear by 6 days, peak by 14 days, and then gradually decline in number (Ankerhold et al., 1998). O4/E587-positive oligodendrocytes in culture display a morphology similar to E587-expressing glial cells in vivo. In contact with axons, oligodendrocytes in vitro begin to differentiate, form processes around axons, and express $36 \mathrm{~K}$ myelin protein (Bastmeyer et al., 1993, 1994). The 36K/ E587-positive oligodendrocytes identified here in the optic nerves of large fish 8 days after ONS are therefore considered to represent oligodendrocytes in a process of dedifferentiation which results in elongate
E587-positive, 36K-negative cells. Consistent with this, we find no evidence of lesion-induced oligodendrocyte apoptosis. Moreover, only a minor fraction of oligodendrocytes incorporated BrdU. This speaks against a significant loss of oligodendrocytes by apoptosis or large-scale replacement of the lost cells. Altogether, our results suggest an adaptive plasticity of goldfish oligodendrocytes which benefits the repair of the fish visual pathway. This plasticity is not observed in mammals (Wood and Bunge, 1991; Crowe at al., 1997; Bartholdi and Schwab, 1998) and may have been lost during vertebrate evolution (Lang et al., 1995, 1996).

The fate of oligodendrocytes in injured CNS fiber tracts in mammals is not well understood. In the spinal cord, oligodendrocytes in ascending and descending tracts undergo apoptosis between $6 \mathrm{~h}$ and 3 weeks after injury (Crowe et al., 1997). Myelin debris and associated inhibitors persist for weeks. Together with reactive astrocytes, this hinders the elongation of regenerative sprouts (for review, see Schwab et al., 1993). In the fish optic nerve, regenerating axons regrow when myelin debris is still abundant. Axon regeneration and myelin removal are temporally overlapping events (Strobel and Stuermer, 1994; Battisti et al., 1995). The suggestion that goldfish oligodendrocytes undergo apoptosis in response to optic nerve lesion resulted from the belief that the path of reelongating axons must be free of obstacles to regeneration imposed by mature oligodendrocytes (Sivron and Schwartz, 1993). The outcome of a series of experiments (Carbonetto et al., 1987; Vanselow et al., 1990; Bastmeyer et al., 1991; Wanner et al., 1995; Lang et al., 1995) speaks against an inhibitory influence of goldfish oligodendrocytes and CNS myelin on axon growth.

In their reaction to axon lesion, goldfish oligodendrocytes resemble Schwann cells (Fawcett and Keynes, 1990; Fu and Gordon, 1997; Schwalb et al., 1995, 1996), although they are distinct cell types. Schwann cells in vitro, for instance, express the cell recognition molecule neurolin and the low-affinity nerve growth factor (NGF) receptor (Bastmeyer et al., 1994) which are not found in oligodendrocytes. Moreover, characteristic features of myelin forming Schwann cells in vivo are the ultrastructure of the myelin sheath (Jeserich and Waehneldt, 1986b), the occurrance of a basal lamina, and the investment of each axonal segment by an individual Schwann cell (Scherer and Easter, 1983).

Although goldfish oligodendrocytes promote axon growth, they still might undergo apoptosis in response to ONS whereupon newly generated cells replace those eliminated. The TUNEL technique detected ap- 

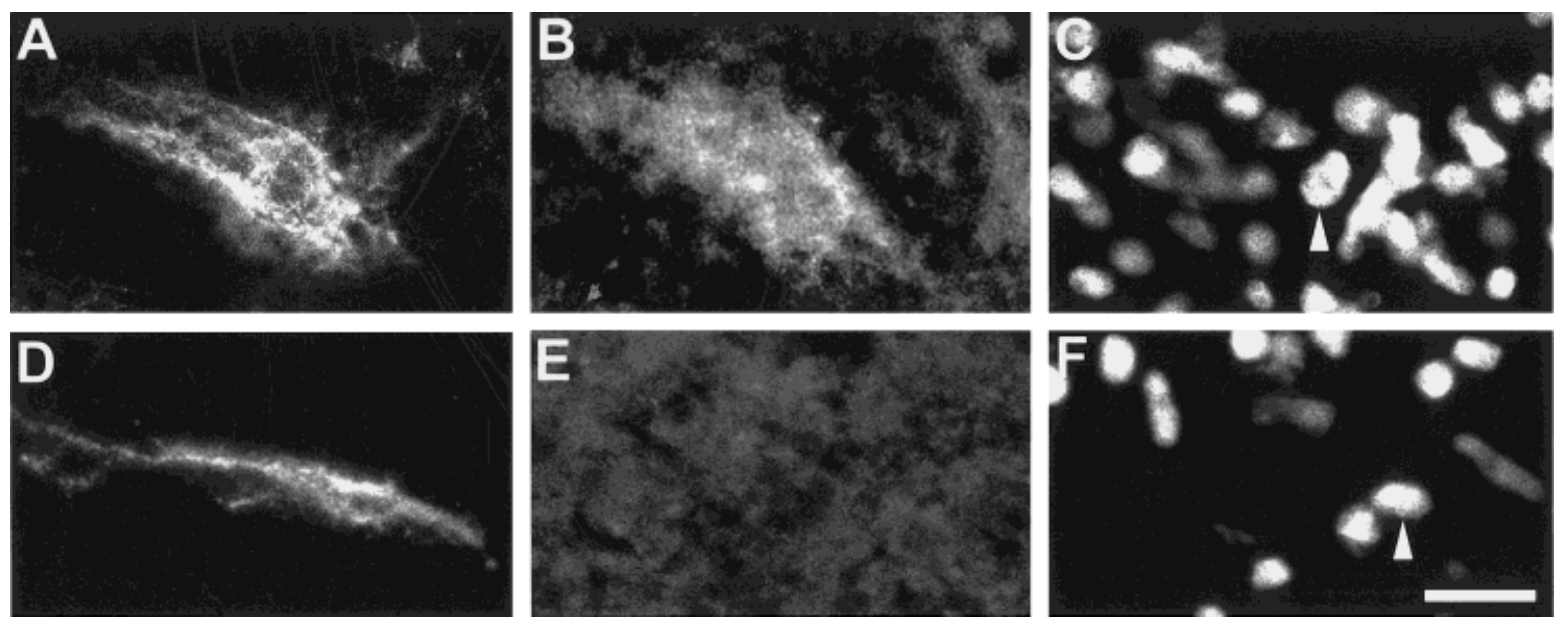

Figure 6 Identification of dedifferentiating oligodendrocytes in vivo. (A) An E587-positive oligodendrocyte in the optic nerve, double-labeled by anti $36 \mathrm{~K}(\mathrm{~B})$ and its nucleus revealed by DAPI [(C), arrowhead]. (E) An elongate E587-positive but anti-36K-negative cell and its DAPI-labeled nucleus [arrowhead, (F)]. Scale bar $=20 \mu \mathrm{m}$.

optotic cells, but these were in the interfascicular spaces and not within the fascicles. This rules out the possibility that they are oligodendrocytes.

To estimate how many TUNEL-positive cells would be expected if oligodendrocytes underwent apoptosis, we determined the approximate number of oligodendrocytes per cross section $(14 \mu \mathrm{m})$ by taking into account (a) the mean number of myelinated axons present in the optic nerves of 3.4- and 7.7-cm-long fish (Easter et al., 1981); (b) the number of myelin segments per oligodendrocyte; and (c) the average length of the myelin segments. This information was obtained from Lucifer yellow-injected oligodendrocytes. Moreover, it was reported that dying oligodendrocytes are detectable for at least $1 \mathrm{~h}$ (Barres et al., 1992). Based on this information, our calculation gave the following values: In cross sections through optic nerves of small and large fish, we would expect to detect 8 and 11.2 TUNEL-positive cells, respectively, if oligodendrocytes died within 3 days after ONS; 4.8 and 6.7 TUNEL-positive cells, respectively, if apoptosis of oligodendrocytes occurred over 5 days; 3.4 and 4.8 cells, respectively, if this occurred over 7 days; and 1.7 and 2.4 cells if oligodendrocyte apoptosis took place over 14 days. Clearly, these numbers do not conform with the present results.

The absence of TUNEL-positive cells from the fascicles also implies that reticular astrocytes do not undergo apoptosis. This, in turn, is consistent with the observation that the fascicle structure of the nerve to which these cells contribute is preserved during axon degeneration and regeneration after ONS. Extrafascicular spaces are rich in fibroblasts, granulocytes, granular macrophages, and numerous cell types of the cellular defense system (Dowding et al., 1991; Strobel and Stuermer, 1994; Battisti et al., 1995; Hirsch et al., 1995). Microglial cells and foamy macrophages occur within the fascicles and are involved in the removal of myelin debris (Dowding et al., 1991; Battisti et al., 1995). It is conceivable that they divide after lesion (Gehrmann et al., 1995) and contribute to the population of BrdU-incorporating intrafascicular cells. However, as phagocytic cells they are capable of traversing the boundaries between fascicular and interfascicular spaces (Battisti et al., 1995), which may explain why we see only small changes in cell number after lesion in the intrafascicular compartment. Moreover, they produce various cytokines and other factors which effect many of the lesion-induced changes (Guilian, 1984; Gehrmann et al., 1995).

Goldfish macrophages were proposed to synthesize cytotoxic factors and induce apoptosis in differentiated mammalian oligodendrocytes in vitro (Sivron et al., 1991; Eitan and Schwartz, 1993). These factors were postulated to cause apoptotic death of goldfish oliodendrocytes in vivo, but direct evidence for such events has not been provided. The absence of TUNEL-positive cells from the fascicles suggests that oligodendrocytes (and astrocytes) most likely survive after ONS. This is consistent with the present finding showing that the minority of oligodendrocytes had incorporated BrdU.

The fish visual pathway must have precursor cells for the generation of astrocytes and oligodendrocytes to accomodate the newly added axons (Maggs and Scholes, 1986) generated during the continuous 


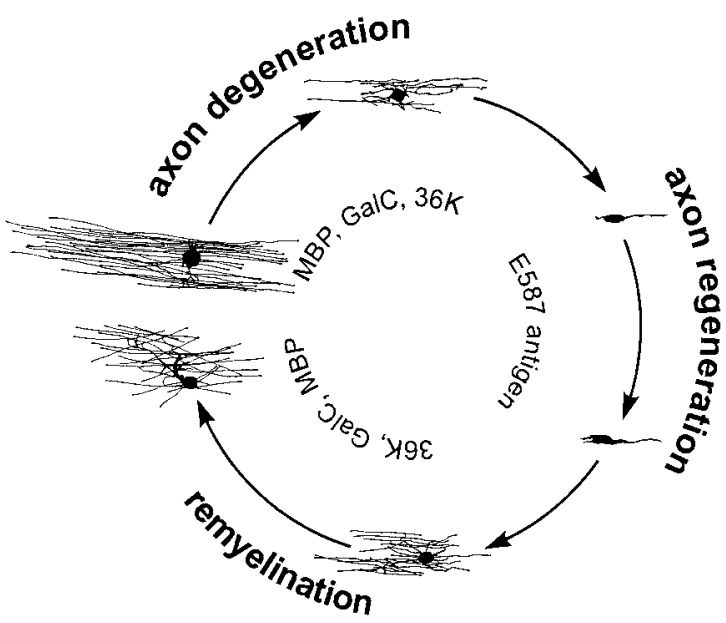

Figure 7 The fate of oligodendrocytes in the goldfish visual pathway. Following optic nerve lesion, mature oligodendrocytes seem to revert into dedifferentiated E587positive elongate cells which redifferentiate into myelinating oligodendrocytes, reexpressing advanced myelin marker molecules.

growth of the fish (Easter et al., 1981). We demonstrate here the presence of O4/anti-BrdU-positive oligodendrocytes among the plated cells derived from freshly dissociated nerve/tracts of BrdU-exposed fish, but few of the oligodendrocytes had undergone cell division. Our analysis is restricted to cells adhering to the coverslip. Unfortunately, the $\mathrm{O} 4$ antibody fails to reveal cells in vivo (see Materials and Methods). E587 antibody stains regenerating axons in addition to glial cells (Vielmetter et al., 1991; Ankerhold et al., 1998) and allows detection of glial cells as long as the number of regenerating axons is small, but in vivo quantification of dividing cells at the relevant stages after ONS is impractical. Still, a sufficiently large number of O4-positive cells was obtained by dissociating and plating nerve/tract glial cells in each experiment and three independent experiments gave similar results.

As new cells are a minor fraction, most O4-positive cells present in the fish optic nerve/tract postlesion must have derived from old cells. This implies that oligodendrocytes undergo a transition from myelin protein synthesizing to dedifferentiated cells (Fig. 7). In fact, the anti-36K/E587 double-labeled cells identified in large fish appear to be oligodendrocytes in the process of dedifferentiation. The elongate bipolar E587-positive and anti-36K-negative cells which markedly increase between 6 and 14 days after ONS (Ankerhold et al., 1998) likely represent the dedifferentiated ones (Fig. 7). This also argues against the possibility that cells coexpressing both markers are redifferentiating oligodendrocytes. The number of regenerating axons in the optic nerve is small when 36K/E587-positive cells are identified and the tectum has not been reached. Moreover, breakdown and removal of old axons and myelin debris are progressing at this time. Signs of myelin protein synthesis and the reappearance of remyelinating oligodendrocytes are found much later, i.e., in small fish from 20 days and in large fish from 6 weeks after ONS onward.

Complex branched, remyelinating oligodendrocytes reappear in correlation with events such as synapse reformation by RGC axons in the tectum and the decline of E587 synthesizing cells (Ankerhold et al., 1998). The elongate, dye-filled cells in intervening stages are reminiscent of the E587-positive dedifferentiated oligodendrocytes. This is not proof, but it is correlative evidence in support of the view that oligodendrocytes undergo morphological and expressional changes during RGC axon degeneration and regeneration (Fig. 7).

Thus, fiber tracts capable of regeneration exhibit adaptive changes in the accompanying glial cells. This has been reported in the vertebrate PNS in general, in the fish and amphibian visual system (Lang et al., 1995; Lang and Stuermer, 1996), and in the fish spinal cord analyzed to date (Wanner, 1997). However, where axonal regeneration is blocked, in the frog spinal cord (Lang et al., 1995) and in most tracts of the mammalian CNS, no signs of a timely dedifferentiation of glial cells (oligodendrocytes) are detectable (Vaughn und Pease, 1970; Carbonell et al., 1991; Butt and Kirvell, 1996). It would be interesting to know whether the neuronal competence for spontaneous axon regeneration and the competence of the glial cells to respond to axon degeneration and regeneration are causally linked or have evolved in parallel.

This study was supported by grants from the DFG and Fonds der Chemischen Industrie (FCI) to CAOS. RA was a fellow of the Boehringer Ingelheim Foundation (BIF). The authors thank Dr. Martin Bastmeyer for discussions and help during completion of the manuscript.

\section{REFERENCES}

Ankerhold R, Leppert CA, Bastmeyer M, Stuermer CAO. 1998. E587 antigen is upregulated by goldfish oligodendrocytes after optic nerve lesion and supports retinal axon regeneration. Glia 23:257-270.

Barres BA, Hart IK, Coles HS, Burne JF, Voyvodic JT, Richardson WD, Raff MC. 1992. Cell death and control of cell survival in the oligodendrocyte lineage. Cell 70: $31-46$.

Bartholdi D, Schwab ME. 1998. Oligodendroglial reaction 
following spinal cord injury in rat: transient upregulation of MBP mRNA. Glia 23:278-284.

Bastmeyer M, Beckmann M, Schwab ME, Stuermer CAO. 1991. Growth of regenerating goldfish axons is inhibited by rat oligodendrocytes and CNS myelin but not by goldfish optic/tract oligodendrocyte-like cells and fish CNS myelin.Identification of astrocyte- and oligodendrocyte-like cells of goldfish optic nerves in culture. J Neurosci 11:626-640.

Bastmeyer M, Bähr M, Stuermer CAO. 1993. Fish optic nerve oligodendrocytes support axonal regeneration of fish and mammalian retinal ganglion cells. Glia 8:1-12.

Bastmeyer M, Jeserich G, Stuermer CAO. 1994. Similarities and differences between fish oligodendrocytes and Schwann cells in vitro. Glia 11:300-314.

Battisti WP, Wang J, Bozek K, Murray M. 1995. Macrophages, microglia and astrocytes are rapidly activated after crush injury of the goldfish optic nerve: a light and electron microscopic analysis. J Comp Neurol 354:306320.

Bunge RP, Hopkins JM. 1990. The role of peripheral and central neuroglia in neural regeneration in vertebrates. Semin Neurosci 2:509-518.

Butt AM, Kirvell S. 1996. Glial cells in transected optic nerves of immature rats. 2. An immunohistochemical study. J Neurocytol 25:381-392.

Carbonell AL, Boya J, Calvo JL, Martin JF. 1991. Ultrastructural study of the neuroglial and macrophagic reaction to Wallerian degneneration of the adult rat optic nerve. Histol Pathol 6:443-451.

Carbonetto S, Evans D, Cochard P. 1987. Nerve fiber growth in culture on tissue substrates from central and peripheral nervous systems. J Neurosci 7:610-620.

Crowe MJ, Bresnahan JC, Shuman SL, Masters JN, Beattie MS. 1997. Apoptosis and delayed degeneration after spinal cord injury in rats and monkeys. Nat Med 1:73-76.

Dowding AJ, Maggs A, Scholes J. 1991. Diversity amongst the microglia in growing and regenerating fish CNS: immunohistochemical characterization using FL.1, an anti-macrophage monoclonal antibody. Glia 4:345-364.

Easter SS, Rusoff AC, Kish, PE. 1981. The growth and organization of the optic nerve and tract in juvenile and adult goldfish. J Neurosci 1:793-811.

Eitan S, Schwartz M. 1993. A transglutaminase that converts interleukin-2 into a factor cytotoxic to oligodendrocytes. Science 261:106-108.

Fawcett JW, Keynes RJ. 1990. Peripheral nerve regeneration. Annu Rev Neurosci 13:43-60.

Fu SY, Gordon T. 1997. The cellular and molecular basis of peripheral nerve regeneration. Mol Neurobiol 14:47-116.

Gavrieli Y, Sherman Y, Ben-Sasson SA. 1992. Identification of programmed cell death in situ via specific labeling of nuclear DNA fragmentation. J Cell Biol 119:493-501.

Gaze RM. 1970. The formation of nerve connections. London: Academic Press.

Gehrmann J, Matsumoto Y, Kreutzberg GW. 1995. Microglia: intrinsic immunoeffector cell of the brain. Brain Res Rev 20:269-287.
Grafstein B. 1986. The retina as a regenerating organ. In: Adler R, Farber DB, editors. The retina: a model for cell biological studies. New York: Academic Press. p 275335.

Guilian D. 1984. Peptides from the regenerating central nervoeus system of goldfish stimulate glia. Proc Natl Acad Sci USA 81:3567-3571.

Hirsch S, Cahill MA, Stuermer CAO. 1995. Fibroblasts at the transection site of the injured goldfish optic nerve and their potential role during retinal axonal regeneration. J Comp Neurol 360:599-611.

Jeserich G, Weahneldt TV. 1986a. Characterization of antibodies against major fish CNS myelin proteins: immunoblot analysis and immunohistochemical localization of $36 \mathrm{~K}$ and IP2 proteins in trout nerve tissue. J Neurosci Res 15:147-158.

Jeserich G, Weahneldt TV. 1986b. Bony fish myelin: evidence for common major structural glycoproteins in central and peripheral myelin of the trout. J Neurochem 46:525-533.

Lang DM, Rubin B, Schwab ME, Stuermer CAO. 1995. CNS myelin and oligodendrocytes of the Xenopus spinal cord-but not optic nerve-possess nonpermissive substrate properties for axon growth. J Neurosci 15:99-109.

Lang DM, Ankerhold R, Stuermer CAO. 1996. Axonal regeneration in the fish and amphibian CNS: myelinassociated neurite growth inhibitors and adaptive plasticity of glial cells. In: Juurlink BHJ, Devon RM, Doucette JR, Schreyer DJ, Verge VMK, editors. Cell biology and pathology of myelin: evolving biological concepts and therapeutic approaches. New York: Plenum. p. 299-308.

Lang DM, Stuermer CAO. 1996. Adaptive plasticity of Xenopus glial cells in vitro and after CNS fiber tract lesions in vivo. Glia 18:92-106.

Maggs A, Scholes J. 1986. Glial domains and nerve fiber order in the fish retinotectal pathway. J Neurosci 6:424438.

Murray M, Edwards MA. 1982. A quantitative study of the reinnervation of the goldfish optic tectum following optic nerve crush. J Comp Neurol 209:363-373.

Scherer SS, Easter SS Jr. 1984. Degenerative and regenerative changes in the trochlear nerve of goldfish. J Neurocytol 13:519-565.

Schwab ME, Kapfhammer JP, Bandtlow CE. 1993. Inhibitors of neurite growth. Annu Rev Neurosci 16:565-595.

Schwalb JM, Boulis NM, Gu M-f, Winickoff J, Jackson PS, Irwin N, Benowitz LI. 1995. Two factors secreted by goldfish optic nerve induce retinal ganglion cells to regenerate axons in culture. J Neurosci 15:5514-5525.

Schwalb JM, Gu MF, Stuermer C, Bastmeyer M, Hu GF, Boulis N, Irwin N, Benowitz LI. 1996. Optic nerve glia secrete a low-molecular-weight factor that stimulates retinal ganglion cells to regenerate axons in goldfish. Neuroscience 72:901-910.

Sivron T, Cohen A, Hirschberg DL, Jeserich G, Schwartz M. 1991. Soluble factor(s) produced in injured fish optic nerve regulate the postinjury number of oligodendrocytes: possible role of macrophages. Glia 4:591-601. 
Strobel G, Stuermer CAO. 1994. Growth cones of regenerating retinal axons contact a variety of cellular profiles in the transected goldfish optic nerve. J Comp Neurol 346: 435-448.

Stuermer CAO, Easter SSJr. 1984. A comparison of the normal and regenerated retinotectal pathways of goldfish. J Comp Neurol 223:57-76.

Vanselow J, Schwab ME,Thanos S. 1990. Responses of regenerating rat retinal ganglion cell axons to contacts with central nervous system myelin. Eur J Neurosci 2:121-125.

Vaughn JE, Pease DC. 1970. Electron microscopic studies of Wallerian degeneration in rat optic nerves. II. Astrocytes, oligodendrocytes and adventitial cells. J Comp Neurol 140:207-226.

Vielmetter J, Lottspeich F, Stuermer CAO. 1991. The monoclonal antibody E587 recognizes growing (new and regenerating) retinal axons in the goldfish retinotectal pathway. J Neurosci 11:3581-3593.
Wanner M, Lang DM, Bandtlow CE, Schwab ME, Bastmeyer M, Stuermer CAO. 1995 Reevaluation of the growthpermissive substrate properties of goldfish optic nerve myelin and myelin proteins. J Neurosci 15:7500-7508.

Wanner M. 1997. Regeneration absteigender Faserbahnen im Rückenmark und Charakterisierung relevanter Bereiche des Zentralnervensystems des Goldfisches. Doctoral dissertation, University of Konstanz.

Wolburg H. 1981. Myelination and remyelination in the regenerating visual system of the goldfish. Exp Brain Res 43:199-206.

Wood PM, Bunge RP. 1991. The origin of remyelinating cells in the adult central nervous system: the role of the mature oligodendrocyte. Glia 4:225-232.

Wyllie AH. 1981. Cell death: a new classification separating apoptosis from necrosis. In: Bowen ID, Lockshin RA, editors. Cell death in biology and pathology. New York: Chapman \& Hall. p 9-34. 